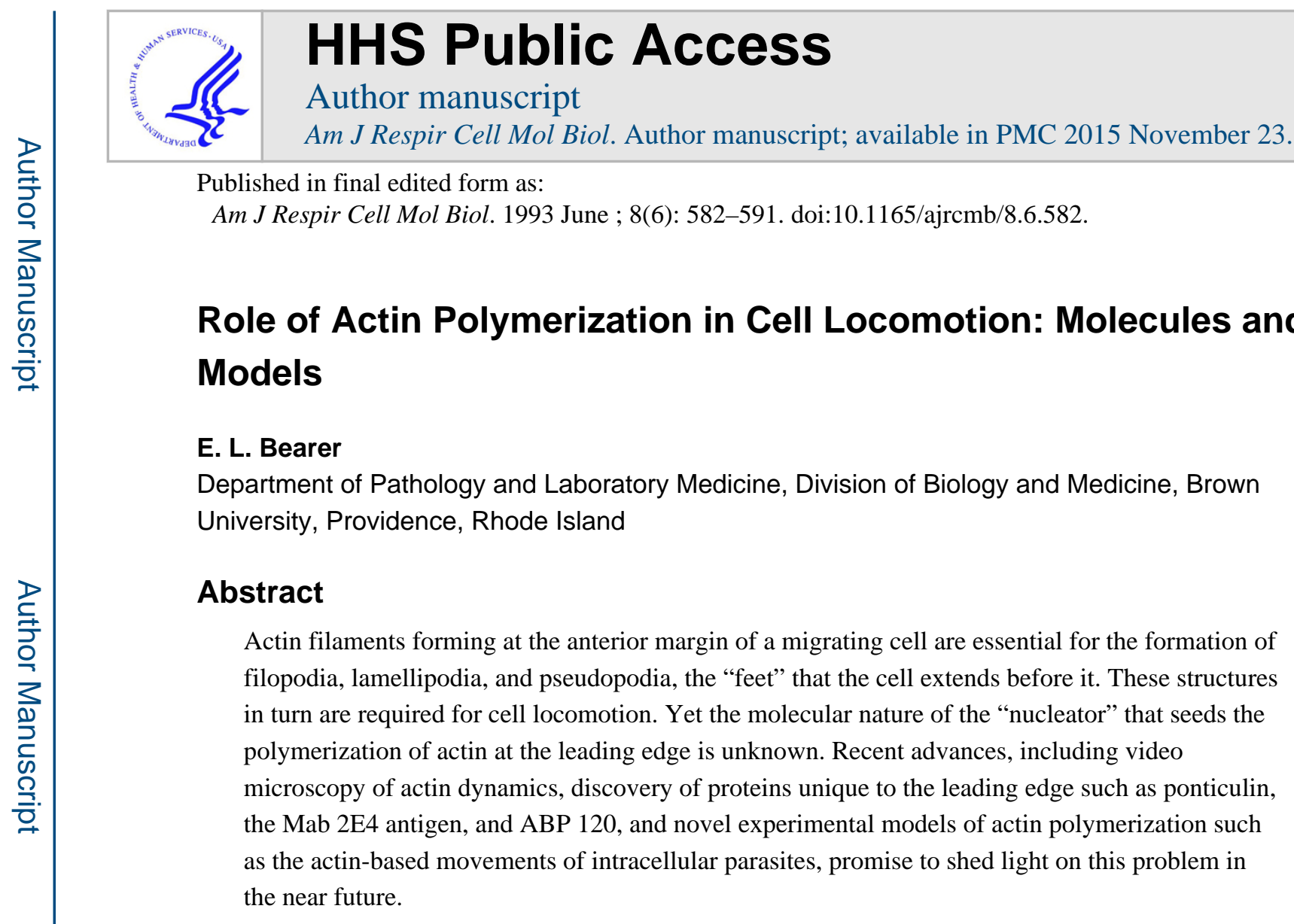

Actin is an abundant structural protein present in virtually all eukaryotic cells. It participates in a range of cellular behaviors, including the elaboration of filaments in the leading edge of the migrating cell, the maintenance of membrane integrity, the contraction of muscle cells, and the formation of cleavage furrows during cell division. This review will focus on the dynamics of actin filament formation during cell motility.

It has long been known that integrity of actin filament network is required for cell locomotion. Observations in fixed cells revealed that the barbed end of actin filaments was present at the leading edge, or outermost margin, of the lamellipodium of motile cells (1). Because this end preferentially elongates during polymerization of the purified ATP-actin in vitro (2-5), it was inferred that the extension of the leading edge in the motile cell involved addition of actin monomers to the membrane-bound barbed end of existing filaments in the leading edge (6). Indirect experiments using video microscopy to observe the behavior of rhodamine-labeled actin injected into the cell supported this idea (7-9). Recently, this hypothesis has been confirmed by several experiments in which the behavior of the lamellipodium of the living cell was observed with video microscopy. Biotin-labeled actin, either injected into motile cells or applied to permeabilized cells, demonstrated that incorporation does indeed primarily occur at the membrane-filament interface $(10,11)$. In addition, photoactivation of "caged" fluorescent actin (an actin-fluorochrome conjugate that emits light only after photoactivation) after its incorporation into filaments in the lamellipodium showed that the filaments move backwards from the membrane attachment

Address correspondence to: E. L. Bearer, M.D., Ph.D., Department of Pathology and Laboratory Medicine, Division of Biology and Medicine, Brown University, Providence, RI 02912. 
site, further substantiating addition of monomer at the membrane surface (12). Finally, direct visualization of the regrowth of filaments off the membrane surface during recovery after depolymerization with cytochalasin revealed that the outermost edge of the lamellipodium is the site from which new filaments form $(13,14)$. Taken together, these results demonstrate a treadmilling off the membrane surface as shown in Figure 1.

These observations demonstrate two phenomena: (1) that actin monomer adds to the membrane-bound end of the filament, and (2) that filaments either grow inwards from a stationary edge, or press outwards upon the edge itself, possibly generating enough force to advance it across the substrate. Major questions remain concerning both of these phenomena. For example, what is the molecular nature of the machine that promotes the nucleation or elongation of filaments on the cytoplasmic surface of the membrane, and how is that molecular machine regulated? In addition, can elongation of actin filaments produce force, and is that force enough to cause outward deformation of the plasma membrane?

\section{Actin Polymerization}

Purified ATP-actin will spontaneously polymerize into filaments upon addition of salt. This process involves two major steps: nucleation of dimers and trimers, and their subsequent elongation into filaments (96). Chemical cross-linking reveals that there are two types of dimers (15): one potentiates elongation, while the other does not, although it can be incorporated into filaments. The assays currently being used to study the kinetics of actin polymerization are not sensitive enough to detect the formation of dimers and trimers. However, when purified ATP-actin is gel-filtered so that only monomeric species are present, and then induced to polymerize, an initial lag period occurs before polymers can be detected. If trimers (three actin molecules bound together) are added to the solution of monomer, explosive polymerization ensues (16). Thus, the lag period is thought to represent the time required for the monomer to self-associate, i.e., the limiting step in kinetics of polymerization is trimer formation. Now that it is possible to visualize dimers directly with fluorescence video microscopy (17), the kinetics of their formation can be analyzed.

Proteins that bind to actin affect the rate and extent of polymerization. The proteins discussed in this review are listed in Table 1, along with a synopsis of their most significant effects. This review will not present a shopping list of the large number of actin-binding proteins, but will focus on cell behaviors and the proteins implicated in those behaviors. There are other classes of proteins, including those which sever and depolymerize actin filaments, that have no demonstrable role in actin polymerization, and these will not be included in this discussion.

Monomer-binding proteins sequester monomer, decreasing the polymerizable pool of actin monomer. Thus, actin does not polymerize in the presence of stoichiometric amounts of monomer-binding proteins. Thymosin $\beta 4$, initially thought to be a thymic hormone, has turned out to be a high-affinity actin monomer-binding protein that is present in cells at high enough concentrations to be responsible for maintaining half of the cytoplasmic actin in the unpolymerized (globular or $\mathrm{G}$ ) state $(19,21,22)$. Thymosin $\beta 4$ is a small $(5 \mathrm{kD})$ protein originally isolated from human blood platelets (21). It is not yet clear how actin bound to 
thymosin $\beta 4$ is released during cell activation when the ratio of filamentous $(\mathrm{F})$-actin to Gactin increases. One possibility that has been proposed is that the barbed ends of actin filaments have a higher affinity for G-actin than thymosin $\beta 4$ (19). There are several homologous family members, and vertebrate cells often contain two different isoforms. The $\beta 10$ isoform also binds actin monomer (23). The family members share a hexapeptide sequence, LKHAET, also found in actobindin (61), which may on its own inhibit actin polymerization.

Profilin also binds actin monomer, and was thought to inhibit actin polymerization in vitro. These results were puzzling, however, because profilin is not present in many cells at high enough levels to explain the large pool of G-actin. Furthermore, profilin is inhibited by phosphatidylinositol 1,4 bisphosphate ( $\mathrm{PIP}_{2}$ ) from binding to actin (24). During cell activation, phosphorylation of phospholipase $\mathrm{C} \gamma(\mathrm{PLC} \gamma)$ increases its affinity for $\mathrm{PIP}_{2}$, allowing it to displace profilin from the membrane (62). This is opposite to the effect one might expect for a protein that decreases actin polymerization, since PLC $\gamma$ activation induces actin filament formation. This paradox is resolved by very recent experiments in which it has been shown that when bound to actin, profilin catalyzes the exchange of ADP for ATP bound to actin monomer $(18,25)$, while thymosin $\beta 4$ inhibits nucleotide exchange (18). Because both molecules have rapid on-off rates, profilin can overcome the inhibition of thymosin $\beta 4$.

ATP-actin has a 10-fold lower critical concentration (concentration of monomer at which filaments are stable) than ADP-actin (3-5). Thus, increasing the ratio of ATP- to ADP-actin would decrease the critical concentration inside cells or vice versa. Since cell activation results in rapid remodeling of the actin cytoskeleton, it almost surely produces a lot of ADPactin, released from depolymerizing filaments. Nucleotide exchange on actin monomers in the absence of profilin is very slow. Thus, profilin is hypothesized to play a role analogous to the GTPase-activating proteins that accelerate the exchange of GDP for GTP on GTPases such as the ras oncogene (18). This nucleotide exchange reloads the GTPase for a subsequent round of signal-transducing hydrolysis. Profilin may "re-load" actin monomer for a subsequent round of polymerization.

In addition to monomer-binding proteins, capping proteins have often been implicated in inducing polymerization. Capping proteins bind to the barbed end of an actin filament and prevent elongation at that end but "nucleate" elongation from the pointed, or slow-growing, end. In addition, they inhibit depolymerization by preventing monomer loss from the barbed end. Capping proteins can be divided into two major groups-the gelsolin/villin family of calcium-dependent capping proteins, some of which also sever filaments, and the CapZ, $32 / 34 \mathrm{kD}$ dimer family of capping proteins that are not regulated by calcium. There is as yet no direct evidence that polymerization from the pointed end of the filament occurs in cells. However, if a large population of short capped filaments were to suddenly become uncapped, such as could occur if agonists induced the capping protein to dissociate from the filament, then explosive polymerization would result $(50,63)$.

Gelsolin (28), gCAP 39 (30, 31), Cap Z (33-35), and ABP70 (aginactin) (39) are some of the candidates for players in this scenario. The biochemical characterization of gelsolin has 
been extensively reviewed elsewhere (27). Most significantly, it has been shown that overexpression of gelsolin in fibroblasts causes them to migrate faster into a wound (64). This confirms a role for gelsolin in motility. However, since gelsolin also severs filaments $(26,28)$, increased motility is very likely to be caused by the severing of filaments in stress fibers and the consequent loss of firm adhesions rather than by stimulation of filament formation by capping/uncapping. Recently, direct observation of the interactions of these proteins with individual actin filaments has become possible through the use of fluorescence video microscopy (26). In this way, it was definitively demonstrated for the first time that gelsolin binds the sides of actin filaments before severing them and remains attached to one end after the filament breaks. Furthermore, severing activity could easily be observed even when present in semi-pure mixtures of actin-binding proteins obtained by filamentous actin affinity chromatography (26). Two dramatic examples of the direct visualization of the severing of individual actin filaments are shown in Figure 2.

End-binding can also be visualized with this video technique (26, 42). Actin filaments adhere by one end to coverslips coated with purified capping proteins such as gCap 39, Cap $\mathrm{Z}$ (26), or the potential barbed-end nucleator, the Mab 2E4 antigen (42), as discussed below. An example of end-binding is shown in Figure 3.

gCAP 39 is a smaller homologue of gelsolin which caps filaments but does not sever them. Unlike gelsolin, gCAP 39 is rapidly released from actin filaments when calcium is chelated by $\operatorname{EGTA}(23,26)$.

Cap Z was originally isolated from muscle but has now been found to be expressed in virtually all cell types (reviewed in reference 36). Cap Z is present in a wide range of species from yeast to human. Knock-out mutations of the beta subunit of Cap $\mathrm{Z}$ in yeast produced cells that had lost actin filament cables (32). Mutant cells were large and round and grew more slowly than wild type. Furthermore, chitin, a cell wall component normally restricted to the junction between mother cell and bud, became diffuse. The mutants resembled temperature-sensitive mutants in the essential gene for actin. This suggests that Cap Z plays some regulatory role in actin filament integrity.

Aginactin was initially isolated as an activity that inhibited polymerization in resting cells $(38,39)$. This inhibitory activity falls by $50 \%$ by $5 \mathrm{~s}$ after stimulation with cyclic adenosine monophosphate, a powerful chemoattractant. This decrease in activity parallels the increase in nucleation activity and the change in cell shape that accompany agonist stimulation. Thus, stimulation may cause aginactin to dissociate from actin filaments, permitting explosive polymerization.

Recently, two other proteins, ponticulin and the Mab 2E4 antigen, have been uncovered that may participate in nucleation from a membrane surface $(41,42,45)$. Both of these proteins were identified by F-actin affinity chromatography, which enriches for low-abundant proteins, although by different protocols $(41,42,65)$. Ponticulin, isolated from the slime mold Dictyostelium discoideum, is a putative transmembrane F-actin-binding protein of 17 $\mathrm{kD}$ in molecular weight. Ponticulin appears to be a relatively abundant protein $(0.05 \%$ of total cell protein) that links actin filaments by their sides to the plasma membrane. Purified 
ponticulin reconstituted into micelles of lipids extracted from Dictyostelium increases the rate of pyrene fluorescence, a quantitative indicator of actin polymerization, as compared to micelles alone or even micelles of purified non-Dictyostelia lipids containing ponticulin (44). This result suggests that ponticulin nucleates actin assembly, although the concentration of actin $(3 \mu \mathrm{M})$ used in these studies was 5 -fold higher than the critical concentration even for pointed-end elongation $(0.6 \mu \mathrm{M})$. Any actin-binding protein that binds to actin trimers thereby increasing their stability would accelerate polymerization. This could well be one of the mechanisms of membrane-associated polymerization under conditions in which the nascent filaments form parallel to the membrane.

The Mab 2E4 antigen is not as well characterized as ponticulin (40-42). It was isolated from activated human blood platelets rather than from slime mold, and eluted from filamentous actin columns with ATP. It has subsequently been shown to be present in the leading edge of the lamellipodium of migrating fibroblasts and the growth cone of nerve-growth factorstimulated PC-12 cells (42). In the fluorescence video microscope assay described above (26), it was shown to bind the ends of actin filaments. This binding is inhibited by ATP but is unaffected by calcium. The Mab 2E4 antigen can be entirely extracted from cell cytoskeletons with detergent and ATP. Because of its location at the ends of actin filaments at sites in the cell where active polymerization is occurring, it is very likely to be involved in that process. Preliminary evidence suggests that it induces the formation of actin oligomers at actin concentrations below the critical concentration for polymerization of purified actin alone (40).

The finding that the Mab 2E4 antigen binds the barbed ends of actin filaments raises the conundrum of how a protein bound to the end of a filament could catalyze elongation of the filament from that end. One hypothetical scenario is that ATP hydrolysis causes Mab 2E4 antigen to release the growing filament, much in the way myosin releases the filament during its stroke, Release of the filament permits the addition of monomer. Once ATP is hydrolyzed, the antigen again binds the filament that has elongated. A similar scenario has been proposed for insertin, also possibly an ATP-sensitive barbed-end binding protein (43).

The Mab 2E4 antigen may be part of a complex of proteins, like a machine, each of which contributes a part of this process. Other members of the complex would include a protein that holds the growing filament in place, and an activator of the complex itself. There are several good candidates for the other components of such a complex, which will be discussed below. Since most of the actin polymerization at the leading edge appears to occur with a perpendicular orientation to the membrane, this scenario is very likely to occur.

A discussion of potential nucleation candidates is not complete without mentioning the new actin isoforms that have recently been identified by molecular techniques. Actin had traditionally been thought to be a family of three very closely related isoforms, with homologies as great at 80 to $90 \%$ between isoforms and between species as distant as human and yeast. However, new actin-like genes have been found by molecular techniques rather than protein biochemistry with homology to the other isoforms in the range of 45 to $70 \%$. There appear to be three groups of these, which have been identified in yeast (49), human $(46,48)$, and nematode. One that has been most extensively studied, RPV-actin $(46,48)$, 
also known as centractin (47), is present in the centrosome. It appears to be part of the activating complex for cytoplasmic dynein and thus would be expected to be involved in vesicle transport (48). The yeast actin variant, ACT 2 , is only $47 \%$ homologous to yeast actin, and is required for a late stage in the cell cycle, since ACT $2^{-}$cells arrest after forming large buds during division (49). The function of the other isoforms is not yet known. All of the isoforms identified to date have a similar molecular weight to actin.

These novel isoforms could be involved in nucleating actin filaments by mimicking one end of the actin monomer and having a higher affinity for monomer than conventional isoforms. Gamma tubulin, also identified by a molecular genetic approach rather than by protein biochemistry, is a new tubulin isoform that is more divergent from both alpha and beta isoforms than they are to each other (66). Gamma tubulin is present in the centrosome and required for the formation of cytoplasmic microtubules. Thus, it may nucleate microtubule formation by mimicking one end of the tubulin monomer in a similar scenario to the mechanism proposed for actin isoforms in the nucleation of actin filaments.

\section{New Experimental Models of Actin Polymerization}

None of these proteins may be the key regulator of actin polymerization inside the cell. Some of the characteristics one might anticipate in a nucleator are that it catalyzes or stabilizes the formation of nucleation sites, such as trimers of actin, at low actin concentrations. These nucleation sites would then be "primed" for explosive elongation in response to cell stimulation. In the last year, there have been two new avenues of investigation that promise to yield more important clues about the characteristics of the nucleator, and perhaps may contribute to its molecular identification. The first of these are studies of the mechanisms of infectivity of intracellular bacteria, including Listeria monocytogenes and some strains of enteropathogenic Escherichia coli. The second are studies showing that a few of the cationic beads applied to the surface of cells will form "inductopodia," or filopodial-like membrane extensions, that are filled with actin filaments whose formation is presumably induced by the attachment of the bead to the cell surface.

Listeria, and other pathogenic intracellular bacteria, are initially endocytosed by the cell. Inside the cell, they escape from the endocytic vesicle into the cytoplasm. After several hours, they begin to move rapidly (67) within the cytoplasm leaving behind a phase-dense "tail." Electron microscopic analysis revealed that this tail was composed of short actin filaments with their barbed ends towards the bacterium $(67,94)$. Furthermore, bacterial mutants that cannot chemotax in liquid media are fully competent to rocket about within the cell $(29,52)$. This confirms that the intracellular form of movement must employ different machinery than that required for bacterial tumbling in media. Finally, the bacterium cannot induce polymerization of purified actin outside the cell (68). Thus, other eukaryotic proteins must be required. Therefore, it appears that the bacterium somehow recruits the cellular nucleation machinery and propels itself within the cytoplasm by means of actin filaments.

Cytologic studies in which labeled proteins are injected into bacterially infected cells reveal that the "tail" is actually stationary and contains other proteins besides actin, including $a$ actinin, tropomyosin, and profilin $(52,69)$. Chloramphenicol, which arrests protein synthesis 
in bacteria but not in eukaryotic cells, does not stop the bacteria from moving once movement is initiated. Continuous actin polymerization is required for movement. This further supports the idea that the machine that nucleates the filaments is made up primarily of eukaryotic proteins.

The bacterium is propelled forward by the asymmetric polymerization of actin behind it. The filaments themselves do not move, but once polymerized serve as a scaffolding (70). One way this might occur is if the bacterium moves randomly by Brownian motion in the cytoplasm but becomes restricted in falling backwards by the density of the actin filaments behind it. In this way, actin filament growth does not actively push the bacterium forward. In support of this, the rates of Brownian motion in the cytoplasm concur with the rates of bacterial movement. Alternatively, the formation of actin filaments might indeed actively propel the bacterium forward. Thus, actin polymerization alone could generate force. Consistent with this idea is that the rate of bacterial movement is the same as the rate of actin polymerization (70). However, actin filaments are quite flexible when not bound to cross-linking proteins (E. L. Bearer, unpublished observations). Thus, it is unlikely that polymerization alone could produce much directional force upon the bacterium. Finally, actin-based motors, such as myosin, could walk along the filament towards its barbed end, which is located at the tail of the bacterium. Such motors could also push the bacterium forwards.

It is now possible to reproduce this bacterial behavior in a cell-free system composed of cytoplasmic extracts from Xenopus eggs (69). This approach should make it feasible to isolate all of the eukaryotic proteins bound to the bacterial surface and within the tail and to analyze them. This potentially will identify the integral nucleating machine but obviously will not resolve the question of what the membrane anchor is or how the cell activates this machine upon stimulation.

The behavior of bacteria within the cell may also be an aberrant response, not similar to any real cellular behavior. However, two recent observations suggest that this is not the case. Lanthanum or zinc, positively charged heavy metals, when applied to the cell surface are endocytosed by the cell in a manner analogous to the bacterium (71). Once inside the cell, metal-filled endosomes also rocket through the cytoplasm, even sometimes traversing the nucleus, trailing a stationary tail of short actin filaments that are apparently the motor for their movements.

Cationic beads applied to the surface of the growth cone of the Aplysia bag cell move backwards from the outermost edge of the lamellipodium (14). A few of these beads fall upon the lamellipodium, and begin a circuitous dance on the surface of the cell, reminiscent of the behavior of the bacteria (72). Staining with phalloidin reveals that actin filaments have formed beneath the dancing beads. This suggests that a process similar to that which produces the bacterial actin tail also drives the cationic bead around the surface, and demonstrates that the bacterial effect is not an anomaly. However, in contrast to the bacterium, both the beads and the heavy metals must be triggering the entire cellular polymerization machinery, including the activator and the membrane attachment site. 


\section{What Is the Nature of the Activation Machinery?}

In the case of the bacterium, molecular genetics may well answer this question very soon, because the bacterial genome is relatively simple, and some of the behaviors are even encoded by plasmids. A bacterial gene required for initiating intracellular movements in Listeria has been identified, and turns out to have six proline-rich repeats (73). Profilin binds avidly to poly-proline (74). Hence, it is conceivable that recruitment of profilin from the cytoplasm onto the bacterial surface is sufficient to induce the formation of short actin filaments in a halo around the bacterium. However, bacterial mutants have been isolated that nucleate actin filaments but do not rocket through the cytoplasm (75). These findings suggest that nucleation of actin is not sufficient for intracellular bacterial movements.

Among the enteropathogenic $E$. coli strains, one mutant is particularly interesting because it fails to induce the phosphorylation on tyrosine of a eukaryotic protein Hp90.

Phosphorylation of this protein is required for bacterial internalization and subsequent reorganization of the host cell's cytoskeleton (76). Thus, it appears that the bacterium may express a set of gene products all of which are necessary for the intracellular movements. These genes may express proteins that interact with parts of the eukaryotic nucleation machine, stimulating it perhaps along pathways parallel to those activated by chemotactic factor receptors. Different strains of bacteria may make use of different cellular pathways to coopt the cytoskeletal machinery.

In response to wounding or to agonist stimulation, actin polymerization inside cells must be more complex than in vitro and probably more complex than when activated by bacteria. Unlike the bacterial polymerization process, actin growing off the membrane surface appears to remain attached to that surface. Although it has been proposed that a simple change in ionic conditions might induce such polymerization, this model cannot explain the mechanism of the attachment of filaments to the membrane as they grow, nor the uniform orientation of filaments seen in the leading edge or in the bacterial tail.

Definitive identification of the molecular nature of the putative nucleator of actin filaments has proved an intractable problem. There are probably several reasons for this. For example, there may be several different pathways by which actin polymerization is induced inside the cells. Thus, there is no single "nucleator." Another reason is that a nucleator is not likely to be an abundant protein and thus not readily found by protein biochemistry, the approach that has been most widely used. For each actin filament $10 \mu \mathrm{m}$ long (the typical width of the leading edge) and with about 370 monomers/ $\mu \mathrm{m}$ (77), there will only be one nucleator at the barbed end. Hence, there would only be one nucleator for every 3,700 actin monomers. Actin comprises $4 \%$ of the soluble protein of most cells, but only half of the actin is in the polymerized state (36). Therefore, a nucleator would possibly be even less than $2 / 3,700$, or $0.0005 \%$ of the soluble protein. Obviously, this is like finding a needle in a haystack.

This putative nucleator is likely to be a multimeric complex, as are the cytoskeletal motors, dynein, kinesin, and the myosins $(78,79)$. This is because the nucleator performs a group of coordinated activities, which include coupling growth factor stimulation with actin polymerization, recruiting actin monomer from intracellular stores, and associating filaments 
with the plasma membrane. Therefore, some of the components of the machine may not bind directly to actin, nor effect its dynamics in vitro in the absence of the other members of the complex.

Signal transduction by growth factors is beyond the scope of this review. However, some evidence is emerging from such studies concerning the pathway by which actin polymerization is ignited. It has long been known that stimulation of growth factor receptors that utilize tyrosine kinase as the signaling mechanism, such as PDGF-R or EGF-R, induces cytochalasin-sensitive ruffling of the cell surface. Furthermore, GTPases have been shown to be involved, since GTP $\mathcal{S}$, a non-hydrolyzable activator of GTPases, activates membrane ruffling when injected into fibroblasts (80). Recently, it has been shown that rac 1, a member of the ras family of small GTPases, is required for this, since injection of a dominant mutant form of the protein prevented PDGF-stimulated membrane ruffling in NIH 3T3 mouse fibroblastic cells (81). Furthermore, overexpression of an activated form of rac induced the formation of actin filament-rich ruffles across the surface of the cell in the absence of growth factors. Finally, phorbol ester stimulation, which activates protein kinase $\mathrm{C}$ and also results in actin-dependent membrane ruffling, was inhibited by the mutant rac, suggesting that this GTPase acts downstream of protein kinase $\mathrm{C}$ in the signaling pathway. This last result fits with the recent finding that actin polymerization in Dictyostelium membranes is activated by diacyl glycerol, thought to be the secondary messenger metabolite of phospholipase $\mathrm{C}$ which activates protein kinase $\mathrm{C}$ (82).

Another GTP-binding protein homologue involved in actin formation, coronin, has been isolated from Dictyostelium (83). This protein is homologous to the $\beta$ subunit of the multimeric G proteins. In Dictyostelia genetically engineered to lack this protein, membrane ruffles fail to form, and cells cannot divide because the lamellipodium that extend from the outer poles of each daughter cell do not form. Thus, the cells cannot pull themselves apart when dividing on a solid substrate. This is particularly interesting in light of previous experiments that demonstrated that Dictyostelia lacking myosin II divide normally on a solid support but cannot divide when floating in liquid media (53). Thus, these cells use two different mechanisms, both involving actin, to complete cytokinesis.

That the Dictyostelium $\mathrm{G}$ protein is different from that found in $3 \mathrm{~T} 3$ cells may reveal a difference in evolution between slime mold and mammals in the $\mathrm{G}$ protein utilized for ruffling. Alternatively, there may be several different pathways for actin polymerization in both species, each using a different signaling mechanism, and the homologous pathways have not been found yet.

Other parts of the signal pathway remain elusive. How does the GTPase activate actin filament formation? One way might be that it activates a kinase that in turn activates an actin-binding protein by phosphorylation. A number of actin-binding proteins present in the cortical cytoskeleton have been found to be phosphorylated. These include ezrin and its family members talin, moesin, and erythrocyte band 4.1 protein $(84-87,95)$. Ezrin is particularly intriguing in that its time course of phosphorylation after EGF stimulation parallels its incorporation into membrane ruffles and filopodial extensions (85). Confounding these results is the observation that at physiologic salt concentrations, ezrin 
does not bind to actin. Spectrin shows a similar time course of phosphorylation on serine and incorporation into membrane protrusions (85).

\section{Generation of Force}

Actin filaments form at sites in cells where dynamic shape changes are occurring, involving the protrusion of filopodia or formation of a lamellipod. It is thus possible that the addition of monomer to the ends of actin filaments exerts pressure on the membrane, causing it to protrude. However, purified actin filaments as observed by fluorescence microscopy are supple and appear to be able to bend at least $90^{\circ}$ without breaking. Thus, it seems unlikely that without some cross-linking or other form of stiffening they could produce much force. Alternatively, force might also be produced by an actin-based motor, such as myosin I, which would slide one filament out by holding onto it while it walks towards the barbed end of a parallel, stationary filament. There is some evidence in support of these hypotheses:

Dictyostelia mutants lacking the cortical cross-linking protein, ABP 120, have severely deficient pseudopodia and show decreased chemotaxis (86). ABP 120 has some homology to actin-binding protein (ABP 260), a $260 \mathrm{kD}$ protein originally isolated from macrophages which has been demonstrated to be part of the platelet cytoskeleton, linked to the membrane by glycoprotein Ib. The tails of both proteins share a repetitive beta sheet sequence, and the amino-terminus, which contains the actin-binding domain, contains a 27 amino acid repeat that appears to be required for actin binding (88). Human malignant melanoma cell lines that do not express ABP 260 display membrane blebbing, which can be entirely reversed by transformation with a plasmid encoding ABP 260 and its consequent expression (89). It is thus likely that ABP 120 plays a different role in pseudopod formation than ABP 260, despite the homologies. That loss of ABP 120 results in defective pseudopods supports the contention that cross-linking of actin filaments is required for organization of the pseudopod and perhaps for the force required to deform the membrane. This hypothesis and the supporting evidence is given in depth elsewhere (50).

The alternative hypothesis presented above was that myosin motors may contribute to the force that projects a filopod forward (55) or to the assembly of actin filaments (90). Skeletal muscle myosin, myosin II, is approximately $200 \mathrm{kD}$ in molecular weight and has long been known to be required for actin-based contractility. It is a Mg-dependent ATPase that requires actin filaments for its activity. Both the ATPase domain and the actin-binding domain are found in the globular amino acid terminal end, while the rest of the protein stretches out in a long helical tail. It is thought to hydrolyze ATP as it moves along an actin filament towards its barbed end. Cytoplasmic forms of myosin II with similar biochemical characteristics and DNA sequences are present in virtually all cells. These appear to be mainly responsible for contractility, including that occurring in stress fibers and in the cleavage furrow during cytokinesis.

Myosin II is apparently not involved in pseudopodial formation or extension, since Dictyostelia lacking myosin II have normal pseudopodial morphology but fail to divide in liquid media $(53,54)$. However, there has been an explosion of new myosin family members (58), including one in yeast, MYO 2, that may be involved in vesicle sorting (91). Several of 
these have been localized by immunocytochemistry to the lamellipodium of various cells, including Dictyostelium (92) and mammalian tissue culture cells (56, 93). Furthermore, detailed observation of filopodial movements by differential interference contrast (a form of Nomarski optics) coupled with video microscopy demonstrate that there is a force present at the tip sufficient to cause buckling of the process when forward progression is blocked experimentally (90). In addition, analysis of the branch points of elongating filopodia suggest that this force is generated by an actin-based motor. Thus, there appears to be a documented role for actin-based motors, such as the myosins, in filopodial extension and retraction.

Disappointingly, individual knock-out mutations of two of these small myosins have produced only subtle defects $(57,59,93)$. However, it seems that there are many more family members that remain to be studied. Therefore, other myosins present in cells that lack one myosin could substitute for the missing protein. Thus, only when all have been identified will the contribution of these myosins to the complex behavior of the pseudopod be revealed.

\section{Conclusion}

Actin polymerization occurs in cells at the leading edge of the lamellipod during cell migration. A cartoon depicting a composite model of how this polymerization might happen is shown in the color diagram on the cover of this issue of the journal. New monomer (shown in different colors as balloons) adds to existing filaments at the filament-membrane interface. The machine (portrayed as a clown hanging from the membrane) that catalyzes this monomer addition is not known, although a number of candidates have been identified, including ponticulin, the Mab 2E4 antigen, insertin, and aginactin. This machine holds onto one protomer while adding a monomer to the other strand of the growing helical filament. Thus, monomer addition occurs while the machine remains attached to both filament and membrane. In the diagram, a single filament is shown in multiple stages as each successive monomer is added. Thus, the filament becomes longer, moving across the diagram from left to right. The monomer with the star moves backwards from the membrane surface.

Polymerization is accelerated by the release of monomer from monomer-binding proteins such as thymosin $\beta 4$ and the rapid exchange of ADP for ATP bound to the monomers by profilin (monomer-sequestering proteins are suggested by the clown selling balloons jogging across the diagram). As the filament grows, cross-linking proteins (monkey labeled " $\mathrm{C}$ ") bind them together and cause them to stiffen. This produces pressure on the membrane, deforming it. Finally, motor proteins (monkey labeled "M") hold one filament firmly while walking towards the barbed end of an adjacent, stationary filament, thus causing the first filament to be shoved against the membrane, also deforming it outwards.

In summary, the molecular nature of the nucleation machine is still not known, although significant advances have been made in the characterization of membrane-associated nucleation activity. Many of these advances have been the result of powerful new video technologies as well as the application of molecular techniques, including yeast genetics and 
the study of bacterial pathogens. Continuing use of new experimental models and molecular approaches promises to yield the nucleation machine(s) in the near future.

\section{Acknowledgments}

I would like to thank the numerous scientists who have contributed to this review by sending me their reprints and discussing their work with me over the phone. (They are too numerous to list here.) I also wish to thank Bruce M. Alberts (University of California, San Francisco), who gave me the chance to work in his lab and develop my understanding of the actin-based cytoskeleton and to begin the identification of the Mab 2E4 antigen, and Tom Pollard (Johns Hopkins Medical School, Baltimore, MD), who has been a constant source of intellectual support. Finally, my gratitude goes to Robert Golder (Marine Biological Lab, Woods Hole, MA), the artist who captured my diagram on paper. The writer is supported by the Council for Tobacco Research, Grant 3192.

\section{References}

1. Small JV. Organization of actin in the leading edge of cultured cells: influence of osmium tetroxide and dehydration on the ultrastructure of actin meshworks. J Cell Biol. 1981; 91:695-705. [PubMed: 6799521]

2. Pollard TD. Polymerization of ADP-actin. J Cell Biol. 1984; 99:769-777. [PubMed: 6540783]

3. Pollard TD. Rate constant for the reactions of ATP and ADP-actin with ends of actin filaments. J Cell Biol. 1986; 103:2747-2754. [PubMed: 3793756]

4. Wegner A. Head to tail polymerization of actin. J Mol Biol. 1976; 108:139-150. [PubMed: 1003481]

5. Wegner A, Isenberg G. 12-fold difference between critical monomer concentrations of the two ends of actin filaments in physiological salt concentrations. Proc Natl Acad Sci USA. 1983; 80:49224925. [PubMed: 6576365]

6. Tilney LG, Bonder EM, De Rosier DR. Actin filaments elongate from their membrane-associated ends. J Cell Biol. 1981; 90:485-494. [PubMed: 7197276]

7. Wang YL. Reorganization of actin filament bundles in living fibroblasts. J Cell Biol. 1984; 99:1478-1485. [PubMed: 6541223]

8. Wang YL. Exchange of actin at the leading edge of fibroblasts: possible role of treadmilling. J Cell Biol. 1985; 101:597-602. [PubMed: 4040521]

9. Wang YL. Mobility of filamentous actin in living cytoplasm. J Cell Biol. 1987; 105:2811-2816. [PubMed: 3693399]

10. Okabe S, Hirokawa N. Incorporation and turnover of biotin-labeled actin microinjected into fibroblastic cells: an immunoelectron-microscopic study. J Cell Biol. 1989; 109:1581-1595. [PubMed: 2677022]

11. Symons M, Mitchison T. Control of actin polymerization in live and permeabilized fibroblasts. J Cell Biol. 1991; 114:503-513. [PubMed: 1860882]

12. Theriot JA, Mitchison TJ. Actin microfilament dynamics in the locomoting cell. Nature. 1991; 357:257-260. [PubMed: 1589024]

13. Forscher P, Smith S. Actions of cytochalasins on the organization of actin filaments and microtubules in neuronal growth cones. J Cell Biol. 1988; 107:1505-1520. [PubMed: 3170637]

14. Forscher, P.; Smith, S. Cytoplasmic actin filaments move particles on the surface of a neuronal growth cone. In: Herman, B.; Jacobson, K., editors. Optical Microscopy for Biology. Wiley-Liss; New York: 1990. p. 459-471.

15. Millonig R, Salvo H, Aebi U. Probing actin polymerization by intramolecular cross-linking. J Cell Biol. 1988; 106:785-793. [PubMed: 3346326]

16. Yin HL, Stossel TP. Purification and structural properties of gelsolin, a $\mathrm{Ca}^{2+}$ activated regulatory protein of macrophages. Nature. 1980; 218:583-586.

17. Bearer EL. Fluorescence microscopy of single actin filaments labelled with rhodamine. Biol Bull. $1992 ; 183: 361-362$.

18. Goldschmidt-Clermont PJ, Furman MI, Wachsstock D, Safer D, Nachmias VT, Pollard TD. The control of actin nucleotide exchange by thymosin $\beta 4$ and profilin. A potential regulatory 
mechanism for actin polymerization in cells. Mol Biol Cell. 1992; 3:1015-1024. [PubMed: 1330091]

19. Nachmias VT. Small actin-binding proteins: The $\beta$-thymosin family. Curr Opin Cell Biol. 1993; 5:56-62. [PubMed: 8448031]

20. Safer D V, Nachmias T. Isolation of a 5-kilodalton actin sequestering peptide from human blood platelets. Proc Natl Acad Sci USA. 1990; 87:2536-2540. [PubMed: 2320573]

21. Safer D, Elzinga M, Nachmias VT. Thymosin $\beta 4$ and Fx, an actin sequestering protein, are indistinguishable. J Biol Chem. 1991; 268:4029-4032. [PubMed: 1999398]

22. Weber A V, Nachmias T, Pennise CR, Pring M, Safer D. Interaction of thymosin $\beta 4$ with muscle and platelet actin: implications for actin sequestration in resting platelets. Biochemistry. 1992; 31:6179-6185. [PubMed: 1627561]

23. Yu FX, Lin SC, Morrison-Bogorod M, Atkinson MAI, Yin HL. Thymosin $\beta 10$ and thymosin $\beta 4$ are both actin sequestering proteins. J Biol Chem. 1993; 268:502-507. [PubMed: 8416954]

24. Lassing I, Lindberg U. Specific interaction between phosphatidylinositol 4,5-bisphosphate and profilactin. Nature. 1985; 314:472-474. [PubMed: 2984579]

25. Mockrin SC, Korn ED. Acanthamoeba profilin interacts with $\gamma$-actin to increase the rate of exchange of actin-bound adenosine 5'triphosphate. Biochemistry. 1980; 19:5359-5362. [PubMed: 6893804]

26. Bearer EL. Direct observation of actin filament severing by gelsolin and binding by gCap 39 and CapZ. J Cell Biol. 1991; 115:1629-1638. [PubMed: 1661732]

27. Yin HL. Gelsolin: calcium- and polyphosphoinositide-regulated actin-modulating protein. Bioessays. 1990; 7:175-178.

28. Yin HL, Stossel TP. Control of cytoplasmic actin gel-sol transformation by gelsolin, a calciumdependent regulatory protein. Nature. 1979; 281:583-586. [PubMed: 492320]

29. Dabiri GA, Young CL, Rosenbloom J, Southwick FS. Molecular cloning of human macrophage capping protein cDNA. J Biol Chem. 1992; 267:16545-16552. [PubMed: 1322908]

30. Southwick FS, DiNubile MJ. Rabbit alveolar macrophages contain a Ca-sensitive, 41,000-dalton protein which reversibly blocks the barbed ends of actin filaments but does not sever them. J Biol Chem. 1986; 261:14191-14195. [PubMed: 3021731]

31. Yu FX, Johnston PA, Sudhof T, Yin HL. gCap39, a calcium ion- and polyphosphoinositideregulated actin capping protein. Science. 1990; 250:1413-1415. [PubMed: 2255912]

32. Amatruda JF, Cannon JF, Tatchell K, Hug C, Cooper JA. Disruption of the actin cytoskeleton in yeast capping protein mutants. Nature. 1990; 344:352-354. [PubMed: 2179733]

33. Caldwell JE, Waddle JA, Cooper JA, Hollands JA, Casella SJ, Casella JF. cDNAs encoding the beta subunit of CapZ, the actin-capping protein of the Z line of muscle. J Biol Chem. 1989; 264:12648-12652. [PubMed: 2745461]

34. Casella JF, Maack DJ, Lin S. Purification and initial characterization of a protein from skeletal muscle that caps the barbed ends of actin filaments. J Biol Chem. 1986; 261:10915-10921. [PubMed: 3733738]

35. Casella JF, Craig SW, Maack DJ, Brown AE. CapZ (36/32), a barbed end actin-capping protein, is a component of the Z-line of skeletal muscle. J Cell Biol. 1987; 105:371-379. [PubMed: 3301868]

36. Cooper JA. The role of actin polymerization in cell motility. Annu Rev Physiol. 1991; 53:585-605. [PubMed: 2042972]

37. Hall A, Schlein A, Condeelis J. Relationship of pseudopod extension to chemotactic hormoneinduced actin polymerization in amoeboid cells. J Cell Biol. 1988; 109:2207-2213. [PubMed: 2553744]

38. Hall AL, Warren V, Dharmawardhane S, Condeelis J. Identification of actin nucleation activity and polymerization inhibitor in amoeboid cell: their regulation by chemotactic stimulation. J Cell Biol. 1989; 109:2207-2213. [PubMed: 2553744]

39. Sauterer R, Eddy R, Hall A, Condeelis J. Purification and characterization of aginactin, a newly identified agonist related actin-capping protein from Dictyostelium amoebae. J Biol Chem. 1991; 266:24533-24539. [PubMed: 1761553] 
40. Bearer EL. Direct observation of actin filament polymerization. Mol Biol Cell. 1992; 3:37a (Abstr.).

41. Bearer, EL. Actin and actin-associated proteins in Xenopus eggs and early embryos. In: Peterson, R., editor. Cytoskeleton in Development. Vol. 26. Academic Press; New York: 1992. p. 34-52.

42. Bearer EL. An actin-associated protein present in the microtubule organizing center and the growth cones of PC-12 cells. J Neurosci. 1992; 12:750-761. [PubMed: 1372044]

43. Gaertner A, Wegner A. Mechanism of insertion of actin monomers between the barbed ends of actin filaments and barbed end-bound insertin. J Muscle Res Cell Motil. 1991; 12:27-36. [PubMed: 2050808]

44. Chia CP, Sharriff A, Savage SA, Luna EJ. The integral membrane protein ponticulin acts as a monomer in nucleating actin assembly. J Cell Biol. 1993; 120:909-918. [PubMed: 8432731]

45. Luna EJ, Wuestehube LJ, Chia CP, Sharriff A, Hitt AL, Ingalls HM. Ponticulin, a developmentally-regulated plasma membrane glycoprotein mediates actin binding and nucleation. Dev Genet. 1990; 11:354-361. [PubMed: 2096014]

46. Adams MD, et al. Complementary DNA sequencing: expressed sequence tags and human genome project. Science. 252:1651-1656. [PubMed: 2047873]

47. Clark SW, Meyer DI. Centractin is an actin homologue associated with the centrosome. Nature. 1992; 359:246-250. [PubMed: 1356230]

48. Lees-Miller JP, Helfman DM, Schroer TA. A vertebrate actin-related protein is a component of a multisubunit complex involved in microtubule-based vesicle motility. Nature. 1992; 359:244-247. [PubMed: 1528266]

49. Schwob E, Martin RP. New yeast actin-like gene required late in the cell cycle. Nature. 1992; 355:179-182. [PubMed: 1729653]

50. Condeelis J. Are all pseudopods created equal? Cell Motil Cytoskeleton. 1992; 22:1-6. [PubMed: 1581977]

51. Cox D, Condeelis J, Wessels D, Soll D, Kern H, Knecht DA. Targeted disruption of the ABP-120 gene leads to cells with altered motility. J Cell Biol. 1992; 116:943-955. [PubMed: 1310321]

52. Sanger JM, Sanger JW, Southwick FS. Host actin assembly is necessary and likely to provide the propulsive force for intracellular movements of Listeria monocytogenes. Infect Immun. 1992; 60:3609-3619. [PubMed: 1500169]

53. DeLozanne A, Spudich J. Disruption of the Dictyostelium myosin heavy chain gene by homologous recombination. Science. 1987; 236:1086-1091. [PubMed: 3576222]

54. Knecht D, Loomis W. Antisense inactivation of myosin heavy chain gene expression in Dictyostelium discoideum. Science. 1987; 236:1081-1086. [PubMed: 3576221]

55. Spudich JA. Myosin and the regulation of cell motility. Cell Regul (Mol Biol Cell). 1990; 1:1-11.

56. Espereafico EM, Cheney RE, Matteoli M, Nascimento AAC, De Camilli PV, Larson RE, Mooseker MS. Primary structure and cellular localization of chicken brain myosin-V (p190), an unconventional myosin with calmodulin light chains. J Cell Biol. 1992; 119:1541-1557. [PubMed: 1469047]

57. Jung G, Hammer J. Generation and characterization of Dictyostelium cells deficient in a myosin I heavy chain isoform. J Cell Biol. 1990; 110:1955-1964. [PubMed: 2141028]

58. Titus MA, Warrick HM, Spudich JA. Multiple actin-based motor genes in Dictyostelium. Cell Regul. 1989; 1:55-63. [PubMed: 2519618]

59. Titus MA, Wessels D, Spudich JA, Soll D. The unconventional myosin encoded by the myoA gene plays a role in Dictyostelium motility. Mol Biol Cell. 1993; 4:233-242. [PubMed: 8382977]

60. Wessels D, Murray J, Jung G, Hammer J, Soll D. Myosin IB mutants of Dictyostelium exhibit abnormalities in motility. Cell Motil Cytoskeleton. 1991; 20:301-315. [PubMed: 1666340]

61. Vanderkerkhove J, Vancompernole K. Structural relationships of actin-binding proteins. Curr Opin Cell Biol. 1992; 4:36-42. [PubMed: 1558752]

62. Goldschmidt-Clermont PJ, Kim PJ, Machesky LM, Rhee SG, Pollard TD. Regulation of phospholipase Cg1 by profilin and tyrosine phosphorylation. Science. 1991; 251:1231-1233. [PubMed: 1848725] 
63. Stossel TP, Chaponnier C, Ezzell R, Hartwig JH, Janmey PA, Kwiatkowski DJ, Lind SE, Smith DB, Southwick FS, Yin HL, Zaner KS. Nonmuscle actin binding proteins. Annu Rev Cell Biol. 1985; 1:353-402. [PubMed: 3030380]

64. Cunningham CC, Stossel TP, Kwiatkowski DJ. Enhanced motility in NIH 3T3 cells that overexpress gelsolin. Science. 1991; 251:1233-1236. [PubMed: 1848726]

65. Miller KG, Field C, Alberts BM. Actin-binding proteins from Drosophila embryos: a complex network of interacting proteins. J Cell Biol. 1989; 109:2963-2975. [PubMed: 2512303]

66. Oakley BR. Gamma tubulin: the microtubule organizer? Trends Cell Biol. 1992; 2:1-5. [PubMed: 14731630]

67. Tilney LG, Portnoy DA. Actin filaments and growth, movement and spread of the intracellular parasite, L. monocytogenes. J Cell Biol. 1989; 109:1597-1608. [PubMed: 2507553]

68. Tilney LG, Connelly PS, Portnoy DA. Actin filament nucleation by the bacterial pathogen Listeria monocytogenes. J Cell Biol. 1990; 111:2979-2988. [PubMed: 2125302]

69. Theriot JA, Mitchison TJ. Actin polymer dynamics in the propulsion of the intracellular bacterial parasite Listeria monocytogenes. Mol Biol Cell. 1992; 3:3a. (Abstr.).

70. Theriot JA, Mitchison TJ, Tilney LG, Portnoy DA. The rate of actin-based motility of intracellular Listeria $\mathrm{m}$. equals the rate of actin polymerization. Nature. 1992; 352:126-131. [PubMed: 2067574]

71. Heuser JE, Morisaki JH. Time-lapse video microscopy of endosomal "rocketing" in La/Zn treated cells. Mol Biol Cell. 1992; 3:172a. (Abstr.).

72. Forscher P, Lin CH, Thompson C. Novel form of growth cone motility involving site-directed actin filament assembly. Nature. 1992; 357:515-518. [PubMed: 1608453]

73. Kocks C, Gouin E, Tabouret M, Berche P, Ohayon H, Cossart P. L. monocytogenes-induced actin assembly requires the actA gene product, a surface protein. Cell. 1992; 68:521-531. [PubMed: 1739966]

74. Tanaka M, Shibata H. Poly (L-proline)-binding proteins from chick embryo are a profilin and a profilactin. Eur J Biochem. 1985; 151:291-297. [PubMed: 3928377]

75. Kuhn M, Prevost MC, Mounier J, Sansonetti PJ. A non-virulent mutant of Listeria monocytogenes does not move intracellularly but still induces polymerization of actin. Infect Immun. 1990; 58:1048-1058. [PubMed: 2108086]

76. Rosenshine I, Donnenberg MS, Kaper JB, Finlay BB. Signal transduction between enteropathogenic Escherichia coli (EPEC) and epithelial cells: EPEC induces tyrosine phosphorylation of host proteins to initiate cytoskeletal rearrangements and bacterial uptake. EMBO J. 1992; 11:3551-3560. [PubMed: 1396556]

77. Hanson J, Lowy J. The structure of F-actin and of actin filaments isolated from muscle. J Mol Biol. $1963 ; 6: 46-52$.

78. Alberts BM, Myake-Lie R. Unscrambling the puzzle of biological machines: the importance of details. Cell. 1992; 68:415-420. [PubMed: 1531448]

79. Pollard TD. Proteins as machines. Nature. 1992; 355:17-18. [PubMed: 1731196]

80. Symons M, Mitchison T. A GTPase controls cell-substrate adhesion in Xenopus XTC fibroblasts. J Cell Biol. 1992; 118:1235-1244. [PubMed: 1512294]

81. Ridley AJ, Paterson HF, Johnston CL, Diekman D, Hall A. The small GTP-binding protein rac regulates growth factor-induced ruffling. Cell. 1992; 70:401-410. [PubMed: 1643658]

82. Shariff A, Luna EJ. Diacylglycerol-stimulated formation of actin nucleation sites at plasma membranes. Science. 1992; 256:245-247. [PubMed: 1373523]

83. deHostos E, Rehfuess C, Bradtke B, Wadell DR, Albrecht R, Murphy J, Gerisch G. Dictyostelium mutants lacking cytoskeletal protein coronin are defective in cytokinesis and cell motility. J Cell Biol. 1992; 120:163-173.

84. Bretscher A. Purification of an 80,000 dalton protein that is a component of the isolated microvillus cytoskeleton and its location in non-muscle cells. J Cell Biol. 1983; 97:425-432. [PubMed: 6885906] 
85. Bretscher A. Rapid phosphorylation and reorganization of ezrin and spectrin accompany morphological changes induced in A-431 cells by epidermal growth factor. J Cell Biol. 1989; 108:921-930. [PubMed: 2646308]

86. Bretscher A. Microfilament structure and function in the cortical cytoskeleton. Annu Rev Cell Biol. 1991; 7:337-374. [PubMed: 1839710]

87. Furthmayr H, Lankes W, Amieva M. Moesin, a new cytoskeletal protein and constituent of filopodia: its role in cellular function. Kidney Int. 1992; 41:665-670. [PubMed: 1573844]

88. Gorlin J, Yamin R, Egan S, Stewart M, Stossel T, Kwiatkowski D, Hartwig J. Human endothelial actin binding protein (ABP-280, non-muscle filamin): a molecular leak spring. J Cell Biol. 1990; 111:1089-1105. [PubMed: 2391361]

89. Cunningham CC, Gorlin JB, Kwiatkowski J, Hartwig JH, Janmey PA, Byers R, Stossel T. Actinbinding protein requirement for cortical stability and efficient locomotion. Science. 1992; 255:325-327. [PubMed: 1549777]

90. Sheetz MP, Wayne D, Pearlman AL. Extension of filopodia by motor-dependent actin assembly. Cell Motil Cytoskeleton. 1992; 22:160-169. [PubMed: 1423662]

91. Lillie SH, Brown SS. Suppression of a myosin defect by a kinesin-related gene. Nature. 1992; 356:358-361. [PubMed: 1549181]

92. Fukui Y, Lynch TJ, Brzeska H, Korn ED. Myosin I is located at the leading edge of locomoting Dictyostelium amoebae. Nature. 1989; 341:328-331. [PubMed: 2797149]

93. Wagner MC, Barylko B, Albanesi JP. Tissue distribution and subcellular localization of mammalian myosin I. J Cell Biol. 1992; 119:163-170. [PubMed: 1527166]

94. Dabiri GA, Sanger JM, Portnoy DA, Southwick FS. Listeria monocytogenes moves rapidly through the host-cell cytoplasm by inducing directional actin assembly. Proc Natl Acad Sci USA. 1990; 87:6068-6072. [PubMed: 2117270]

95. Lankes WT, Furthmayr H. Moesin: a member of the protein 4.1-talin-ezrin family of proteins. Proc Natl Acad Sci USA. 1991; 88:8297-8301. [PubMed: 1924289]

96. Pollard TD. Actin. Curr Opin Cell Biol. 1990; 2:33-40. [PubMed: 2183841] 


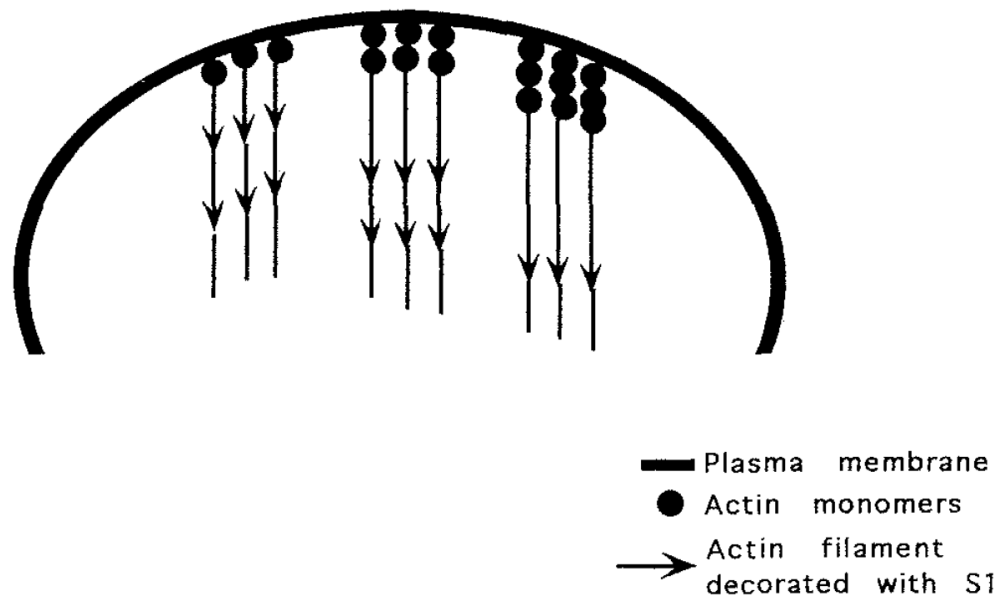

Figure 1.

Actin filaments grow off the plasma membrane. New subunits are added to the growing filament at the membrane-filament interface. When labeled with the SI fragment of myosin, the barbed end of the filament is at the membrane, while the pointed end extends into the cell interior. Monomer must be lost from the pointed end of the filament because, after achieving a uniform length, filaments do not elongate despite the continued addition of subunits to the barbed end. 

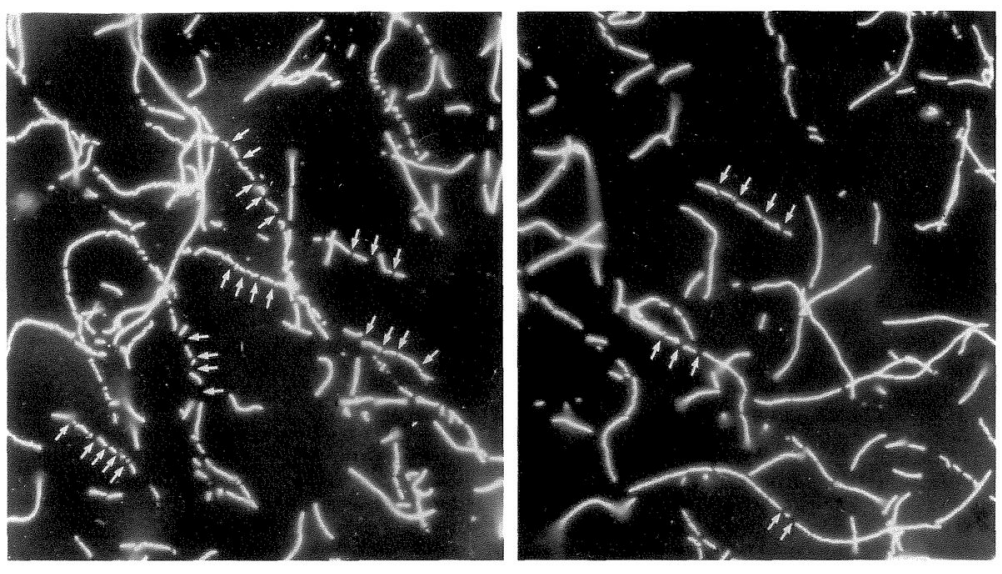

Figure 2.

Rhodamine-phalloidin-stabilized filaments mixed with proteins eluting with ATP from filamentous actin columns are rapidly severed. These events can be visualized by fluorescence microscopy. The small arrows indicate sites where a long filament has been cut. (Reproduced by permission, J. Cell Biol. 115:1629-1638, 1991.) 


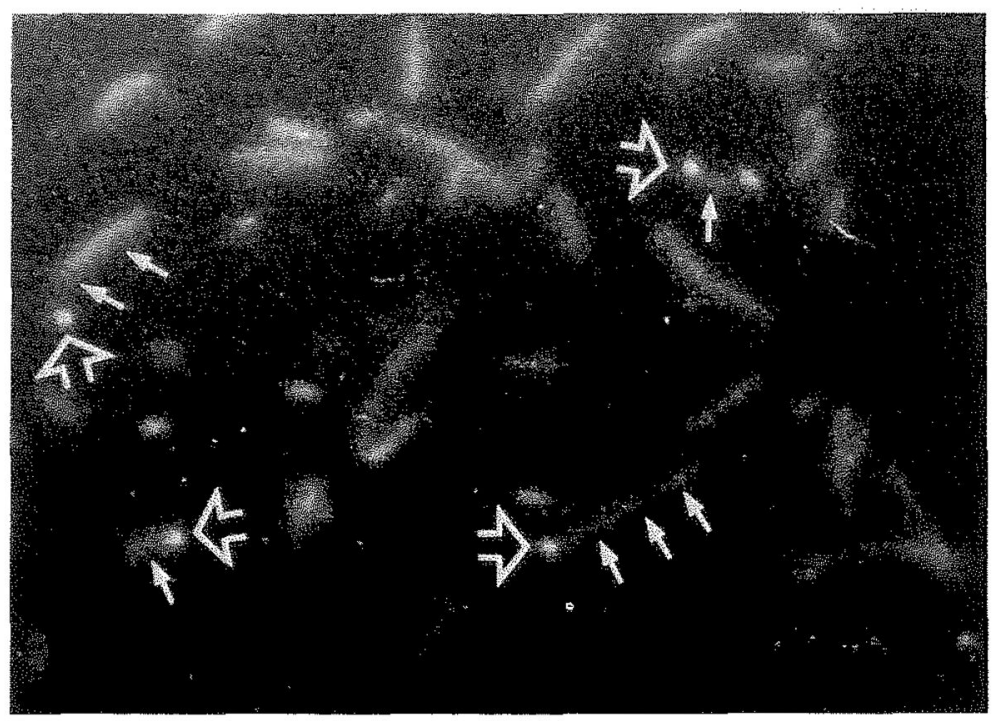

Figure 3.

Actin filaments bind by one end to coverslips coated with capping proteins, such as gCap 39, Cap Z, or the Mab 2E4 antigen. The bound end appears bright in the micrograph (large arrow), while the dangling tail of the filament is often out of focus (small arrows) because it is hanging below the focal plane. Sometimes only the attached end is visible in the micrograph because the unattached length of filament undergoes rapid Brownian motion and does not remain in place long enough to expose the film. (Reproduced by permission, J. Cell Biol. 115:1629-1638, 1991). 
TABLE 1

Examples of actin-binding proteins and their effect on filaments*

\begin{tabular}{|c|c|}
\hline Type of Protein & Effect \\
\hline \multicolumn{2}{|l|}{ Monomer-binding proteins } \\
\hline Thymosin $\beta 4$ and 10 (18-23) & $\begin{array}{l}\text { Sequesters monomer; prevents nucleotide exchange; maintains ADP-actin pool high; } \\
\text { decreases polymerizable pool. }\end{array}$ \\
\hline Profilin $(18,24,25)$ & $\begin{array}{l}\text { Binds monomer; accelerates ATP-ADP exchange on monomer, thereby increases } \\
\text { polymerizability of monomer pool. }\end{array}$ \\
\hline \multicolumn{2}{|l|}{ Capping proteins } \\
\hline Gelsolin $(16,26-28)$ & $\begin{array}{l}\text { Calcium dependent; also severs filaments; nucleates filaments at high actin concentration for } \\
\text { pointed-end elongation. }\end{array}$ \\
\hline gCap 39 (29-31) & Calcium dependent; like gelsolin but does not sever filaments. \\
\hline Cap Z (26, 32-36) & Heterodimer; does not sever; not calcium dependent; required for actin bundles in yeast. \\
\hline Aginactin (37-39) & $70 \mathrm{kD}$ agonist-regulated capping protein. \\
\hline \multicolumn{2}{|l|}{ ATP-sensitive barbed-end binding proteins } \\
\hline Mab 2E4 antigen (40-42) & $\begin{array}{l}\text { Binds barbed ends of actin filaments in vitro; ATP inhibits binding; effect on polymerization } \\
\text { not known. }\end{array}$ \\
\hline Insertin (43) & Decreases rate of polymerization less than expected for a capping protein; inhibited by ATP. \\
\hline \multicolumn{2}{|l|}{ Membrane-associated nucleators } \\
\hline Ponticulin $(44,45)$ & $\begin{array}{l}\text { Nucleates actin assembly in vitro from both ends at high actin concentrations; activated by } \\
\text { lipids; binds the sides of actin filaments. }\end{array}$ \\
\hline \multicolumn{2}{|l|}{ Actin-like proteins } \\
\hline RPV-actin/centractin (46-48) & $\begin{array}{l}\text { Present in the centrosome; > 50\% amino-acid identity with actin; a member of dynein } \\
\text { activation complex, dynactin. }\end{array}$ \\
\hline Act 2 (49) & Yeast actin isoform, $47 \%$ identity with yeast actin; required for cytokinesis. \\
\hline \multicolumn{2}{|l|}{ Cross-linking proteins } \\
\hline ABP $120(50,51)$ & $\begin{array}{l}\text { Homology with filamin (ABP 280); cross-links actin networks in orthogonal arrays; knock- } \\
\text { out mutant has abnormal pseudopodia. }\end{array}$ \\
\hline$a$-actinin (52) & Member of spectrin family; present in actin tails of intracellular bacteria. \\
\hline \multicolumn{2}{|l|}{ Actin-based motors } \\
\hline Myosin II (53-55) & $\begin{array}{l}\text { Large ( } 200 \mathrm{kD}) \text { multimeric ATPase; involved in contractility and cleavage furrow in } \\
\text { cytokinesis. }\end{array}$ \\
\hline Myosins I through V (mini-myosins) (56-60) & $\begin{array}{l}\text { A large family of proteins with actin-dependent ATPase activity and homology in the "head" } \\
\text { domain to myosin II; many have been found present in lamellipodia; no single isoform } \\
\text { shown to be required for locomotion. }\end{array}$ \\
\hline
\end{tabular}

Am J Respir Cell Mol Biol. Author manuscript; available in PMC 2015 November 23. 